\title{
Dust deposition rates derived from optical satellite observations
}

Luca Lelli, W. von Hoyningen-Huene, M. Vountas, M. Jäger and J.P. Burrows

Satellite retrievals of aerosol optical thickness over the Atlantic Ocean have been used to estimate the rates of dust deposition. The results reveal higher dust deposition in summer than in winter and give insights into the location of desertic dust source areas.

Desert dust (or dust aerosol) outflows off the West African coast impact offshore biogeochemical processes and can be regarded as natural hazards to human activities and ecosystems. For example, dust storms affect aviation operations reducing flight visibility, causing engine mechanical damages and flight path reassessments. On the other hand, dust input adds nutrients to the surface of the seas which stimulate phytoplankton production, and higher particle flux can increase export fluxes of biomass from the surface waters to the sea floor and hence increase accumulation rates in the underlying sediments.

Dust is collected on land only at few observation sites, like at Cape Blanc (Mauritania) or Barbados (Fischer and Karakas 2009; Prospero 1999).

Conversely, remote satellite monitoring of dust transport covers the entire Atlantic Ocean and is therefore an invaluable complement to in-situ measurements.

Standard remote sensing techniques of dust are based on the physical principle of extraterrestial sunlight travelling through the Earth's atmosphere and being attenuated by suspended dust particles. Nadirlooking spectral satellite radiometers (e.g. SeaWiFS, MERIS, MISR, MODIS) measure

A
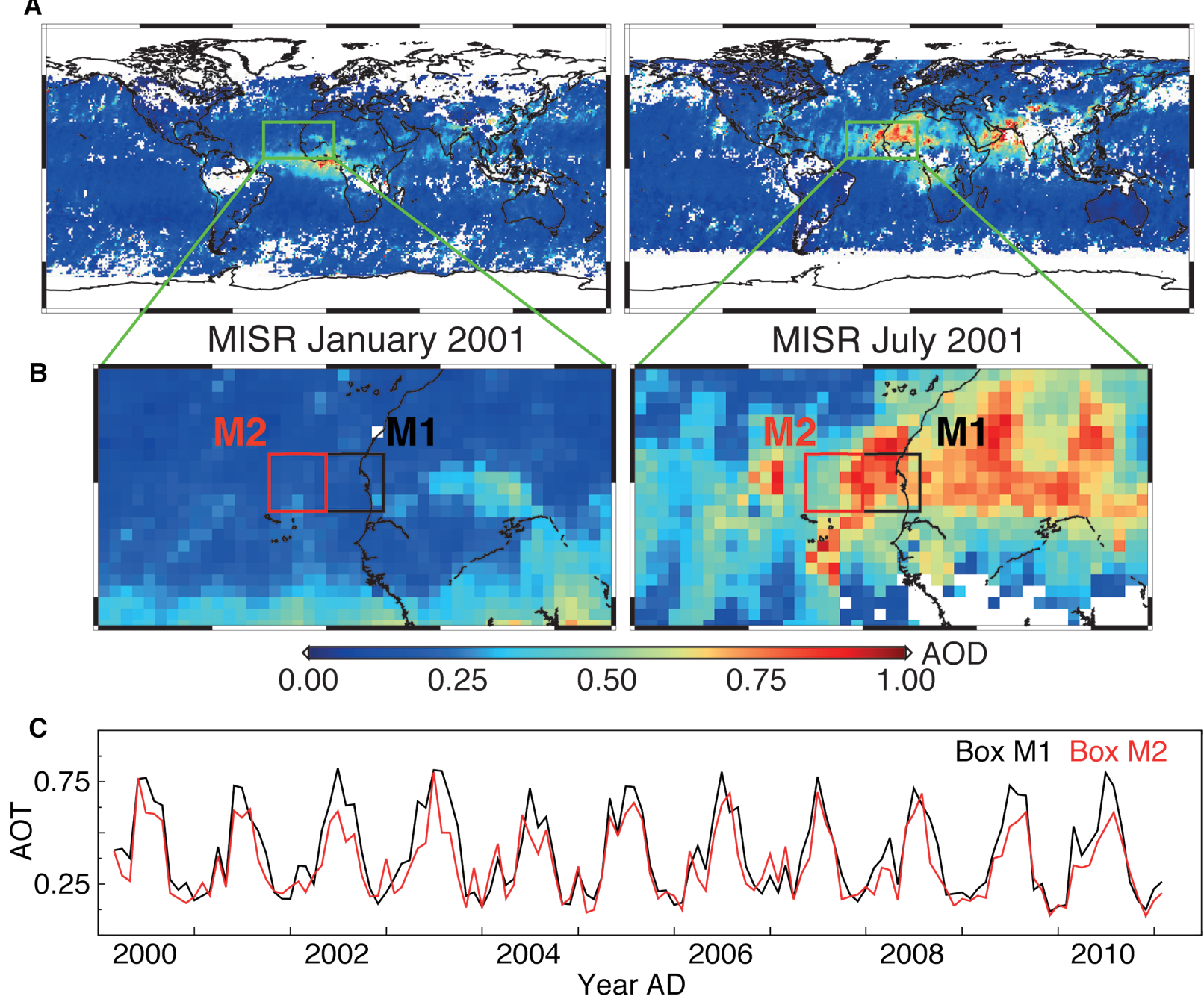

Figure 1: Monthly averages of Aerosol Optical Thickness (AOT; dimensionless) retrieved from MISR satellite data for the determination of dust sedimentation rate. Maps of AOT for January and July 2001 on a global scale (A) and zoomed in to the example region around Cape Blanc (B), where sediment traps are deployed across West Africa and the Atlantic Ocean. The time series in (C) portrays the AOT signal extracted for the adjacent boxes M1 and M2. The oscillations of both curves indicate that dust activity is more frequent in summer than in winter. Dust deposition is reflected by the difference between the red and black curves during the respective months. 




Figure 2: Time series of AOT changes between boxes M1 and M2 (see Fig.1), derived from satellite retrievals from SeaWiFS (black curve) and MISR (blue curve) instruments. The curves can be considered as approximations for the rate of dust deposition at the site of Cape Blanc.

the amount of sunlight reflected back to space and allow us to determine the degree of sunlight attenuation. The latter is described by Aerosol Optical Thickness (AOT), which is defined as the extinction coefficient of light integrated over a vertical column through the atmosphere. AOT can be calculated from data of reflected light with algorithms like the Bremen AErosol Retrieval (BAER; von HoyningenHuene et al. 2003, 2011) and monitored both in space and time. However, such algorithms are challenged not only by missing a-priori information on the specific optical properties of dust (Dinter et al. 2006), but also by local reflectivity of the ground. Radiant surfaces (such as the bright Sahara) may reduce the contrast between suspended dust and the ground beneath, hence degrading the overall algorithmic performance and accuracy.

Figure 1 shows seasonal variations in satellite-derived AOT in dust-laden regions worldwide. Off West Africa, for example, AOT is about three times as high in summer than in winter.

\section{From optical thickness \\ to dust deposition}

Comparisons of satellite-derived AOT and data from sediment traps over West Africa and the Northern Atlantic do not show a direct relationship between atmospheric dust loading and dust accumulation. However, the spatio-temporal change of dust AOT can be used as an indicator for the fallout of aerosol along the transport path. The method described in the following, has been developed to determine dust deposition from satellite data.

The deposition rate of aerosol particles is reflected by the decrease of AOT along the transport path rather than AOT itself. Driven by this idea, a method has been developed to determine the relative change of AOT along an estimated transport path. This requires that the aerosol loading is determined from AOT for the region of interest, i.e. the AOT needs to be transferred quantitatively into aerosol mass load. The algorithm for this is based on assumptions on the dust grain size and dust particle density in the air.

Mass loss (or sedimentation rate) which can be directly compared to ground measurements can be derived from lateral dust transport in two ways: (i) using a transport model with a sedimentation module or (ii) estimating the mass loss from the change in the aerosol columnar mass along the trajectory. Here, the latter approach is followed.

The sedimentation rate is inferred from the mass difference along the main aerosol transport path. If one takes the temporally averaged AOT of two adjacent regional boxes (see boxes $\mathrm{M} 1$ and M2 in Fig. 1) along the main trajectory, a sedimentation rate can be estimated from the difference between the red and black AOT curves (Fig. 1C). Our new method allowed us to produce estimates of dust deposition from monthly averages of AOT on a regional grid.

\section{Testing the method}

Preliminary qualitative comparisons have been made for Cape Blanc on the coast of Mauretania, using deposition data by Fischer and Karakas (2009). First, AOT values were calculated with the BAER algorithm using SeaWiFS data. Then, two grid boxes over the site and offshore Cape Blanc were selected. The two neighboring boxes are located between $20^{\circ} \mathrm{N}$ and $22^{\circ} \mathrm{N}$ (see M1 and M2, Fig. 1). We assume that both boxes are located along the main westward oriented dust transport path. Even though this assumption is only of limited validity and the time series of the difference between AOT in both boxes shows some negative values (Fig. 2), the analysis of the time series reveals a potentially promising correlation $(r>0.6)$ between the AOT derived from remote sensing and in-situ sedimentation data from Cape Blanc (unpublished, not shown). Figure 2 also shows that the method is sensitive to the satellite radiometers used. The pictured values of AOT changes, derived from SeaWiFS and MISR measurements, exhibit differences that can be attributed to distinct instrumental characteristics.

These preliminary results are a first step towards a systematic application of this method. However, the approach needs significant improvements in terms of the consideration of dust transport trajectories, the injection height of dust, its mixing with surrounding air and optical parameters used for determining the local dust type.

\section{AFFILIATIONS}

Institute of Environmental Physics and Remote Sensing (IUP), University of Bremen, Germany

\section{CONTACT}

Luca Lelli: luca@iup.physik.uni-bremen.de

\section{REFERENCES}

Fischer G, Karakas G (2009) Biogeosciences 6: 85-102 Prospero JM (1999) J Geophys Res 13: 15917-15927 Von Hoyningen-Huene W et al. (2003) J Geophys Res 108, doi: 10.1029/2001JD002018

Von Hoyningen-Huene W et al. (2011) Atmos Meas Tech 4: $151-171$

Dinter T et al. (2009) Tellus 61: 229-238 